\title{
Neighborhood Socioeconomic Status, Depression, and Health Status in the Look AHEAD (Action for Health in Diabetes) Study
}

Tiffany L Gary-Webb ${ }^{1,2,3^{*}}$, Kesha Baptiste-Roberts ${ }^{2}$, Luu Pham ${ }^{4}$, Jacqueline Wesche-Thobaben ${ }^{5}$, Jennifer Patricio ${ }^{6}$, F Xavier Pi-Sunyer ${ }^{6}$, Arleen F Brown ${ }^{7}$, LaShanda Jones-Corneille ${ }^{8}$, Frederick L Brancati ${ }^{2,3}$ and for the Look AHEAD Research Group

\begin{abstract}
Background: Depression and diminished health status are common in adults with diabetes, but few studies have investigated associations with socio-economic environment. The objective of this manuscript was to evaluate the relationship between neighborhood-level SES and health status and depression.
\end{abstract}

Methods: Individual-level data on 1010 participants at baseline in Look AHEAD (Action for Health in Diabetes), a trial of long-term weight loss among adults with type 2 diabetes, were linked to neighborhood-level SES (\% living below poverty) from the 2000 US Census (tracts). Dependent variables included depression (Beck Inventory), and health status (Medical Outcomes Study (SF-36) scale). Multi-level regression models were used to account simultaneously for individual-level age, sex, race, education, personal yearly income and neighborhood-level SES.

Results: Overall, the \% living in poverty in the participants' neighborhoods varied, mean $=11 \%$ (range 0-67\%). Compared to their counterparts in the lowest tertile of neighborhood poverty (least poverty), those in the highest tertile (most poverty) had significantly lower scores on the role-limitations(physical), role limitations(emotional), physical functioning, social functioning, mental health, and vitality sub-scales of the SF-36 scale. When evaluating SF-36 composite scores, those living in neighborhoods with more poverty had significantly lower scores on the physical health ( $\beta$-coefficient $[\beta]=-1.90$ units, 95\% Cl: $-3.40,-0.039)$, mental health $(\beta=-2.92$ units, $-4.31,-1.53)$ and global health $(\beta=-2.77$ units, $-4.21,-1.33)$ composite scores.

Conclusion: In this selected group of weight loss trial participants, lower neighborhood SES was significantly associated with poorer health status. Whether these associations might influence response to the Look AHEAD weight loss intervention requires further investigation.

\section{Background}

Despite the surge of literature evaluating the neighborhood environment and general health, there is only a smaller, growing body of literature evaluating neighborhood and mental health outcomes [1]. Most previous studies have examined the perception of neighborhood problems with depression, anxiety, and health status [2-7], with only a few using objective measures of the neighborhood environment [8]. Overall, most studies

\footnotetext{
* Correspondence: tlg2124@columbia.edu

'Department of Epidemiology, Columbia Mailman School of Public Health, New York, NY, USA

Full list of author information is available at the end of the article
}

were multi-level and showed that more neighborhood problems or detrimental aspects of the physical environment are associated with worse mental health, particularly, depression.

It is well known that individuals with diabetes experience more depression and diminished health status compared to those without diabetes $[9,10]$. Therefore, to explore potential contributions to this relationship, it is important to understand the association between objective neighborhood context, health status, and depression among individuals with diabetes. We conducted a multilevel, cross-sectional analysis at baseline in the Look AHEAD study (a multicenter controlled trial in 5,145

\section{Biomed Central}


overweight adults with type 2 diabetes designed to determine the long-term health effects of interventions to achieve intentional weight loss) to determine the association between neighborhood and weight-related health behaviors [11]. Results showed several significant associations with neighborhood and weight control behaviors for food and physical activity. In this manuscript, we evaluated the association between neighborhood poverty and the expanded outcomes of individuallevel health status and depression.

\section{Methods}

\section{Study Population of the Parent Study}

The primary objective of the Look AHEAD (Action for Health in Diabetes) study $[12,13]$ is to examine, in overweight volunteers with type 2 diabetes, the longterm effects of an intensive lifestyle intervention program designed to achieve and maintain weight loss by decreased caloric intake and increased physical activity. The intervention group is compared to a control condition involving a program of diabetes education and support. The primary basis for the comparison is the incidence of serious cardiovascular events. Other outcomes, including cardiovascular disease risk factors, diabetes-related metabolic factors and complications, and the cost-effectiveness of the intensive intervention are also studied. Participants are 5,145 volunteers with type 2 diabetes who are 45-75 years of age and overweight or obese (body mass index [BMI] $\geq 25 \mathrm{~kg} / \mathrm{m}^{2}$ ).

\section{Study Population of the Ancillary Study}

This ancillary study was conducted using baseline (before the intervention) data from Look AHEAD participants at 4 clinical sites; Baltimore $(\mathrm{n}=302)$, Philadelphia $(\mathrm{n}=293)$, Pittsburgh $(\mathrm{n}=321)$, and New York $(\mathrm{n}=$ 303). Sites were chosen because of their close geographic proximity relative to all of the Look AHEAD clinical sites and similar demographic profile (predominately white and African-American). The total study sample for this ancillary consists of 1010 participants with complete data on neighborhood environment and other key variables. Addresses were used to identify the corresponding census tracts for each participant (neighborhood) as defined by the 2000 US Census using a process called geocoding and software program ArcGISTM. The program matches imported addresses to geographic maps and other geographic data. Matches are rated with scores from 0 (no match) to 100 (perfect match); we accepted matches with $80 \%$ certainty or more. Once we identified the census tracts and corresponding data for each participant, these data were linked to the individual-level participant data collected during the Look AHEAD trial.

\section{Main Data Sources}

Data are derived from the 2000 US Census long form and include demographic characteristics (age, race, sex), housing characteristics (housing structure, number of rooms), economic characteristics (occupation, place of work and journey to work) and financial characteristics (value of home, rent, utilities cost) for each census tract.

Participants in the Look AHEAD study underwent extensive data collection at baseline, including interview, physical examination, and blood and urine assays [12]. Although the trial will last over 10 years, this manuscript is restricted to data collected at baseline only. The Look AHEAD trial was approved by the Johns Hopkins School of Medicine Institutional Review Board.

\section{Key Independent Variables}

Using the census data, indices of neighborhood socioeconomic status (SES) developed by Diez-Roux and Winkleby/Cubbin were created using variables such as the $\%$ of persons living below poverty, $\%$ of adults with a college degree, median household income, \% of persons earning interest income, \% of adults in executive/ managerial occupations, and \% of adults who are unemployed. To produce comparable data for the Diez-Roux and Cubbin indices used in previous studies [14-16], we presented them along with the single item "\% of individuals in the census tract living below the federal poverty line" because this measure is highly correlated with other census-based indices and has been shown to be similarly predictive of health outcomes [16].

Covariates were individual-level socio-demographic characteristics: sex, age in years, education in years, race (black, White, Hispanic or other), and categories of yearly, personal income. Body Mass Index (BMI) was presented to show that, per Look AHEAD eligibility criteria, all participants were overweight or obese.

\section{Key Dependent Variables}

The Medical Outcomes Study (MOS) Short Form-36 Health Survey (SF-36), a multidimensional scale of health status designed for self or interviewer administration was used to measure health status $[17,18]$. The SF36 has demonstrated reliability and validity and is widely used in health outcomes research [19]. The SF-36 measures 8 health domains: 1) Physical functioning, 2) Role limitations because of physical health problems, 3) Bodily pain, 4) Social functioning, 5) General mental health (psychological distress and psychological well-being, 6) Role limitations because of emotional problems, 7) Vitality (energy/fatigue), and 8) General health perceptions. SF-36 responses were recorded on 5-point scales. Scores for each health domain scale range from 0 to 100 , with higher scores indicating better functioning or well being. Composite scores for global, physical, and 
mental health were also calculated [19]. Depressive symptoms were measured using the Beck Depression Inventory [20]; higher scores indicate more depressive symptoms.

\section{Statistical Analysis}

In this analysis, the main independent variables were the neighborhood factors and the main dependent variables were individual-level depression and health status from the Look AHEAD study. Descriptive statistics were used to describe the study population.

Multi-level linear models were used to analyze the aggregate and individual level data [21-23]. Recognizing that when studying group-level variables, individuals are nested within those groups, multi-level analyses are designed to account for this clustering. In the current study, intercept terms were allowed to vary for each cluster (random effect) while all other variables were considered as fixed effects. Multilevel models were used specifying census tract as the cluster variable. They were fit first with the neighborhood level factor (\% poverty) as the independent variable and individual-level depression and health status as outcome variables in separate models. Subsequently, individual-level SES (personal yearly income and education) were added while also controlling for potential confounders (age, sex, race). This enabled us to determine the independent contribution of neighborhood SES entered into the models as tertiles and $\beta$ coefficients comparing the highest tertiles (most poverty) to the lowest tertile (least poverty) are shown in the table.

We also examined if neighborhood was associated with weight and a number of other clinical variables (including glycemic control). Since this ancillary study was set within a randomized controlled trial at baseline, the participants had similar health profiles at the beginning of the study and most of those associations were not significant. Therefore, we did not feel that it was appropriate to adjust for these variables in the analysis. All analyses were conducted using STATA statistical software, version 10 .

\section{Results}

\section{Selected Baseline Characteristics of Study Participants}

Selected baseline characteristics of the study participants are presented in Table 1. Participants were on average $59.2 \pm 6.7$ years of age and $42 \%$ male. The majority were white (64.4\%), 27\% were Black/African American, and $8.3 \%$ were of "other" races. About a third of participants had at least some college education and about $52 \%$ had a college education or more; the majority of participants had annual income $>\$ 40,000$. All participants were at least overweight or obese (BMI $>25 \mathrm{~kg} /$ $\mathrm{m}^{2}$ ), eligibility criteria for Look AHEAD. Participant
Table 1 Selected Characteristics of 1010 Look AHEAD Participants

\begin{tabular}{|c|c|}
\hline Socio-demographic Characteristics & \\
\hline Age (years) & $59.2 \pm 6.7$ \\
\hline \multicolumn{2}{|l|}{ Sex } \\
\hline Male & $421(41.7)$ \\
\hline \multicolumn{2}{|l|}{ Education (years) } \\
\hline$\leq 12$ & $161(15.9)$ \\
\hline $13-16$ & 329 (32.6) \\
\hline $16+$ & $520(51.5)$ \\
\hline \multicolumn{2}{|l|}{ Race } \\
\hline Black & $276(27.3)$ \\
\hline White & $650(64.4)$ \\
\hline Other or Hispanic & $84(8.3)$ \\
\hline \multicolumn{2}{|l|}{ Income } \\
\hline$<\$ 20,000$ & $74(7.3)$ \\
\hline$\$ 20,000-\$ 40,000$ & $181(17.9)$ \\
\hline$\$ 40,000-\$ 60,000$ & $211(20.9)$ \\
\hline$\$ 60,000-\$ 80,000$ & $179(17.7)$ \\
\hline$\geq \$ 80,000$ & $365(36.2)$ \\
\hline Body mass index $\left[\mathrm{BMl}, \mathrm{kg} / \mathrm{m}^{2}\right]$ & $36.2 \pm 5.8$ \\
\hline Overweight [25-29.9] & $132(13.1)$ \\
\hline Obese $[30-39.9]$ & $640(63.4)$ \\
\hline Extreme Obesity $[\geq 40]$ & $238(23.5)$ \\
\hline \multicolumn{2}{|l|}{ Neighborhood Census Tract Indicators } \\
\hline Percent Below Poverty [Range $=0,0.67]$ & $0.11 \pm 0.10$ \\
\hline \multicolumn{2}{|l|}{ Tertile $1(<0.05)$} \\
\hline \multicolumn{2}{|l|}{ Tertile $2(0.05-0.11)$} \\
\hline Tertile $3(>0.11)$ & \\
\hline
\end{tabular}

Cubbin Deprivation Score $[$ Range $=-2.9,2.8] \quad-0.006 \pm 0.79$

Tertile $1(<-0.34)$

Tertile $2(-0.34-0.31)$

Tertile $3(>0.31)$

Diez-Roux Deprivation Score [Range $=-18.7,12.0] \quad 0.003 \pm 5.1$

Tertile $1(<-2.00)$

Tertile $2(-2.00-2.59)$

Tertile $3(>2.59)$

\section{Depression}

Beck Depression Score [Range $=0,30]$ *

$4.72 \pm 4.39$

\section{Health Status}

Physical Functioning [Range $=19,58]$

Role Limitations-Physical [Range $=26,56]$

Bodily Pain [Range $=22,60]$

General Mental Health [Range $=23,60]$

Role Limitations-Emotional [Range $=19,54]$

Social Functioning $[$ Range $=17,57]$

Vitality $[$ Range $=29,65]$

General Health [Range $=23,64]$

General Health Composite Score [Range $=22,61]$

Mental Health Composite Score [Range $=23,62$ ]

$48.51 \pm 7.85$

$44.03 \pm 12.07$

$49.59 \pm 8.68$

$49.40 \pm 6.78$

$46.58 \pm 12.37$

$52.77 \pm 7.60$

$49.98 \pm 6.81$

$45.89 \pm 8.37$

$45.63 \pm 8.89$

$50.08 \pm 7.53$

Physical Health Composite Score [Range $=20,63]$

$47.77 \pm 8.17$

${ }^{*} \mathrm{~N}=948$

All results presented as $\mathrm{N}(\%)$ or mean $\pm \mathrm{SD}$

Higher Cubbin and Diez-Roux score $=$ lower SES 
neighborhoods were diverse. Of all the neighborhoods represented in the study, the mean \% of those living below the federal poverty level was $11 \%$. Overall, there were 920 unique census tracts represented in the study; Baltimore $=201$, New York $=257$, Philadelphia $=245$, Pittsburgh $=217$. The number of participants per census tract ranged from 1-6.

\section{Association between Neighborhood SES, Health Status, and Depression}

Those participants living in neighborhoods with more poverty (highest tertile) had significantly lower scores on the role limitations-physical, role limitations-emotional, physical functioning, social functioning, mental health and vitality sub-scales of the SF-36 health status measure (data not shown). When evaluating SF-36 composite scores (Table 2), those living in neighborhoods with more poverty had significantly lower scores on the physical health $(\beta$-coefficient $[\beta]=-1.90$ units, 95\% CI: $-3.40,-0.039)$, mental health $(\beta=-2.92$ units, $-4.31,-1.53)$ and global health ( $\beta=-2.77$ units, $-4.21,-1.33)$ composite scores. Likewise, those in neighborhoods with more poverty had higher scores (indicating worse symptoms) on the Beck Depression Inventory $(\beta=0.68$ units, -0.12 , $1.48)$, although this finding was not statistically significant. No significant differences were shown for those in the middle tertile of poverty compared to the lowest for health status or depression. Although the associations between the Cubbin and Diez-Roux neighborhood scores and health status were in the hypothesized direction, few were statistically significant.

\section{Discussion}

Our results suggest that among this group of overweight adults with type 2 diabetes in the Look AHEAD study, lower neighborhood SES was significantly associated with poorer health status. These conclusions are supported by results from this study that included a diverse range of neighborhoods, detailed individual-level data, and a large percentage of minority participants.

There were, however, a few limitations. First, using the census tract as a proxy for neighborhood has been criticized, however, many studies have used this indicator, allowing us to compare our findings across studies. Furthermore, the wealth of data available from the US Census provides a comprehensive view of this geographic entity. Similarly, the neighborhood data may not have represented the entire baseline time-period for the Look AHEAD study. Data used were from the 2000 Census and 2004 Consumer database; Look AHEAD participants were recruited from 2001-2004. Neighborhoods are constantly changing, however the time-frame for the data used was close to the study recruitment period. Second, given the eligibility criteria for entry into the study, the population was fairly homogeneous with respect to some factors. One example was weight and clinical variables such as glycemic control, which had little variation by neighborhood. In a future study, we plan to conduct longitudinal analyses and determine how neighborhood influences response to the weight loss intervention. The longitudinal analyses should show more variation in the dependent variables as individuals respond differently to the intervention.

\section{Conclusion}

This study supports the previous literature and gives more evidence for a consistent association between neighborhood poverty and its association with poorer mental health outcomes. Moreover, it gives weight to a strong association when using an objective measure of

Table 2 Adjusted Beta Coefficients and 95\% Confidence Intervals for Neighborhood Indicators, Composite Health Status and Depression among Participants in the Look AHEAD Study

\begin{tabular}{|c|c|c|c|c|c|}
\hline & & Physical Health Composite & Mental Health Composite & Global Health Composite & Beck Depression \\
\hline \multirow{4}{*}{$\begin{array}{c}\text { Below Poverty } \\
(\%)\end{array}$} & 2 & 0.42 & -0.48 & -0.06 & -0.02 \\
\hline & & $(-0.84,1.69)$ & $(-1.49,0.54)$ & $(-1.18,1.06)$ & $(-0.67,0.63)$ \\
\hline & 3 & -1.90 & -2.92 & -2.77 & 0.68 \\
\hline & & $(-3.40,-0.39)$ & $(-4.31,-1.53)$ & $(-4.21,-1.33)$ & $(-0.12,1.48)$ \\
\hline \multirow[t]{4}{*}{ Cubbin Score } & 2 & -0.66 & 0.06 & -0.30 & -0.68 \\
\hline & & $(-1.97,0.65)$ & $(-1.07,1.19)$ & $(-1.52,0.92)$ & $(-1.37,0.00)$ \\
\hline & 3 & -0.47 & -0.78 & -0.78 & -0.58 \\
\hline & & $(-1.98,1.04)$ & $(-2.11,0.55)$ & $(-2.18,0.62)$ & $(-1.36,0.19)$ \\
\hline \multirow[t]{4}{*}{ Diez-Roux Score } & 2 & -0.27 & 0.13 & -0.04 & -0.71 \\
\hline & & $(-1.58,1.04)$ & $(-1.00,1.26)$ & $(-1.26,1.17)$ & $(-1.40,-0.02)$ \\
\hline & 3 & -0.56 & -0.85 & -0.85 & -0.52 \\
\hline & & $(-2.15,1.02)$ & $(-2.25,0.55)$ & $(-2.34,0.64)$ & $(-1.31,0.27)$ \\
\hline
\end{tabular}

All models adjusted for age, sex, education, personal yearly income and race

${ }^{\dagger}$ All represent comparisons to tertile 1 (reference groups)

Higher Cubbin and Diez-Roux score = lower SES 
neighborhood SES which supports the prior studies that focused mostly on perceived measures of neighborhood. Furthermore, this study was conducted in a sample of adults with type 2 diabetes. Persons with diabetes are known to have higher rates of depression $[9,10,24]$, and understanding how other factors influence depression in this population will ultimately contribute to strategies for prevention.

Two recent systematic review articles summarized the state of the literature on neighborhood and mental health, particularly in relation to depression or depressive symptoms $[25,26]$. Although the consistent theme was that few studies attempted to quantify potential mechanisms, many different pathways and mediating variables were hypothesized. For example, Kim and colleagues outlined a conceptual framework that considered several pathways as potential mediators including: 1) physical health as a result of environmental hazards, 2) health behaviors that may be inhibited by features of the physical environment, 3) psychosocial stress as a result of neighborhood disorder and crime, and 4) resources and social capital that might be lacking as a result of suboptimal social environment [26,27]. Mair and colleagues support these hypotheses and suggest that developing more theory on these process features and empirically testing them is fundamental to strengthening causal inference [25]. Consequently, future studies should pay careful attention to these mechanisms order to identify areas for intervention. A recent qualitative assessment using concept mapping has begun this process [1] and should provide the foundation for further development.

\footnotetext{
Acknowledgements

The authors would like to acknowledge the Look AHEAD staff and participants who made this research possible.

This project was funded by grants from the National Institutes of Health. Dr. Gary-Webb was funded by grants from the NIDDK (U01-DK57149-05S1) and NHLBI (K01-HL084700) and Dr. Brancati was funded by a grant from the NIDDK (K24-DK6222). The authors would like to acknowledge the Look AHEAD research group, which has been previously described (ref 12). Look AHEAD Research Group at BaselineClinical Sites The Johns Hopkins Medical Institutions Frederick Brancati, MD, MHS; Debi Celnik, MS, RD, LD; Jeff Honas, MS; Jeanne Clark, MD, MPH; Jeanne Charleston, RN; Lawrence Cheskin, MD; Kerry Stewart, EdD; Richard Rubin, PhD; Kathy Horak, RD

Pennington Biomedical Research Center George A. Bray, MD; Kristi Rau; Allison Strate, RN; Frank L. Greenway, MD; Donna H. Ryan, MD; Donald Williamson, PhD; Elizabeth Tucker; Brandi Armand, LPN; Mandy Shipp, RD; Kim Landry; Jennifer Perault

The University of Alabama at Birmingham Cora E. Lewis, MD, MSPH; Sheikilya Thomas MPH; Vicki DiLillo, PhD; Monika Safford, MD; Stephen Glasser, MD; Clara Smith, MPH; Cathy Roche, RN; Charlotte Bragg, MS, RD, LD; Nita Webb, MA; Staci Gilbert, MPH; Amy Dobelstein; L. Christie Oden; Trena JohnseyHarvard Center

Massachusetts General Hospital: David M. Nathan, MD; Heather Turgeon, RN; Kristina P. Schumann, BA; Enrico Cagliero, MD; Kathryn Hayward, MD; Linda Delahanty, MS, RD; Barbara Steiner, EdM; Valerie Goldman, MS, RD; Ellen Anderson, MS, RD; Laurie Bissett, MS, RD; Alan McNamara, BS; Richard Ginsburg, PhD; Virginia Harlan, MSW; Theresa Michel, MS
}

Joslin Diabetes Center: Edward S. Horton, MD; Sharon D. Jackson, MS, RD, CDE; Osama Hamdy, MD, PhD; A. Enrique Caballero, MD; Sarah Ledbury, MEd, RD; Maureen Malloy, BS; Ann Goebel-Fabbri, PhD; Kerry Ovalle, MS, RCEP, CDE; Sarah Bain, BS; Elizabeth Bovaird, BSN, RN; Lori Lambert, MS, RD Beth Israel Deaconess Medical Center: George Blackburn, MD, PhD; Christos Mantzoros, MD, DSc; Ann McNamara, RN; Heather McCormick, RD University of Colorado Health Sciences Center James O. Hill, PhD; Marsha Miller, MS, RD; Brent VanDorsten, PhD; Judith Regensteiner, PhD; Robert Schwartz, MD; Richard Hamman, MD, DrPH; Michael McDermott, MD; JoAnn Phillipp, MS; Patrick Reddin, BA; Kristin Wallace, MPH; Paulette Cohrs, RN, BSN; April Hamilton, BS; Salma Benchekroun, BS; Susan Green; Loretta Rome, TRS; Lindsey Munkwitz, BS

Baylor College of Medicine John P. Foreyt, PhD; Rebecca S. Reeves, DrPH, RD; Henry Pownall, PhD; Peter Jones, MD; Ashok Balasubramanyam, MD; Molly Gee, MEd, RD

University of California at Los Angeles School of Medicine Mohammed F. Saad, MD; Ken C. Chiu, MD; Siran Ghazarian, MD; Kati Szamos, RD; Magpuri Perpetua, RD; Michelle Chan, BS; Medhat Botrous

The University of Tennessee Health Science CenterUniversity of Tennessee East. Karen C. Johnson, MD, MPH; Leeann Carmichael, RN; Lynne

Lichtermann, RN, BSN

University of Tennessee Downtown. Abbas E. Kitabchi, PhD, MD; Jackie Day, RN; Helen Lambeth, RN, BSN; Debra Force, MS, RD, LDN; Debra Clark, LPN; Andrea Crisler, MT, Donna Green, RN; Gracie Cunningham; Maria Sun, MS, RD, LDN; Robert Kores, PhD; Renate Rosenthal, PhD; and Judith Soberman, $\mathrm{MD}$

University of Minnesota Robert W. Jeffery, PhD; Carolyn Thorson, CCRP; John P. Bantle, MD; J. Bruce Redmon, MD; Richard S. Crow, MD; Jeanne Carls, MEd; Carolyne Campbell; La Donna James; T. Ockenden, RN; Kerrin Brelje, MPH, RD; M. Patricia Snyder, MA, RD; Amy Keranen, MS; Cara Walcheck, BS, RD; Emily Finch, MA; Birgitta I. Rice, MS, RPh, CHES; Vicki A. Maddy, BS, RD; Error! Reference source not found., BS

St. Luke's Roosevelt Hospital Center Xavier Pi-Sunyer, MD; Jennifer Patricio, MS; Jennifer Mayer, MS; Stanley Heshka, PhD; Carmen Pal, MD; Mary Anne Holowaty, MS, CN; Diane Hirsch, RNC, MS, CDE

University of Pennsylvania Thomas A. Wadden, PhD; Barbara J. MaschakCarey, MSN, CDE; Gary D. Foster, PhD; Robert I. Berkowitz, MD; Stanley Schwartz, MD; Shiriki K. Kumanyika, PhD, RD, MPH; Monica Mullen, MS, RD; Louise Hesson, MSN; Patricia Lipschutz, MSN; Anthony Fabricatore, PhD; Canice Crerand, PhD; Robert Kuehnel, PhD; Ray Carvajal, MS; Renee Davenport; Helen Chomentowski

University of Pittsburgh David E. Kelley, MD; Jacqueline Wesche-Thobaben, RN, BSN, CDE; Lewis Kuller, MD, DrPH.; Andrea Kriska, PhD; Daniel Edmundowicz, MD; Mary L. Klem, PhD, MLIS; Janet Bonk, RN, MPH; Jennifer Rush, MPH; Rebecca Danchenko, BS; Barb Elnyczky, MA; Karen Vujevich, RNBC, MSN, CRNP; Janet Krulia, RN, BSN, CDE; Donna Wolf, MS; Juliet Mancino, MS, RD, CDE, LDN; Pat Harper, MS, RD, LDN; Anne Mathews, MS, RD, LDN Brown University Rena R. Wing, PhD; Vincent Pera, MD; John Jakicic, PhD; Deborah Tate, PhD; Amy Gorin, PhD; Renee Bright, MS; Pamela Coward, MS RD; Natalie Robinson, MS, RD; Tammy Monk, MS; Kara Gallagher, PhD; Anna Bertorelli, MBA, RD; Maureen Daly, RN; Tatum Charron, BS; Rob Nicholson, PhD; Erin Patterson, BS; Julie Currin, MD; Linda Foss, MPH; Deborah Robles; Barbara Bancroft, RN, MS; Jennifer Gauvin, BS; Deborah Maier, MS; Caitlin Egan, MS; Suzanne Phelan, PhD; Hollie Raynor, PhD, RD; Don Kieffer, PhD; Douglas Raynor, PhD; Lauren Lessard, BS; Kimberley Chula-Maguire, MS; Erica Ferguson, BS, RD; Richard Carey, BS; Jane Tavares, BS; Heather Chenot, MS; JP Massaro, BS

The University of Texas Health Science Center at San Antonio Steve Haffner, MD; Maria Montez, RN, MSHP, CDE; Connie Mobley, PhD, RD; Carlos Lorenzo, MD

University of Washington/NA Puget Sound Health Care System Steven E. Kahn, MB, ChB; Brenda Montgomery, MS, RN, CDE; Robert H. Knopp, MD; Edward W. Lipkin, MD, PhD; Matthew L. Maciejewski, PhD; Dace L. Trence, MD; Roque M. Murillo, BS; S. Terry Barrett, BS

Southwestern American Indian Center, Phoenix, Arizona and Shiprock, New Mexico William C. Knowler, MD, DrPH; Paula Bolin, RN, MC; Tina Killean, BS; Carol Percy, RN; Rita Donaldson, BSN; Bernadette Todacheenie, EdD; Justin Glass, MD; Sarah Michaels, MD; Jonathan Krakoff, MD; Jeffrey Curtis, MD, MPH; Peter H. Bennett, MB, FRCP; Tina Morgan; Ruby Johnson; Cathy Manus; Janelia Smiley; Sandra Sangster; Shandiin Begay, MPH; Minnie Roanhorse; 
Didas Fallis, RN; Nancy Scurlock, MSN, ANP; Leigh Shovestull, RDCoordinating Center

Wake Forest University School of Medicine Mark A. Espeland, PhD; Judy Bahnson, BA; Lynne Wagenknecht, DrPH; David Reboussin, PhD; W. Jack Rejeski, PhD; Wei Lang, PhD; Alain Bertoni, MD, MPH; Mara Vitolins, DrPH; Gary Miller, PhD; Paul Ribisl, PhD; Kathy Dotson, BA; Amelia Hodges, BS; Patricia Hogan, MS; Kathy Lane, BS; Carrie Combs, BS; Christian Speas, BS; Delia S. West, PhD; William Herman, MD, MPHCentral Resources Centers DXA Reading Center, University of California at San Francisco Michael Nevitt, PhD; Ann Schwartz, PhD; John Shepherd, PhD; Jason Maeda, MPH; Cynthia Hayashi; Michaela Rahorst; Lisa Palermo, MS, MA

Central Laboratory, Northwest Lipid Research Laboratories Santica M. Marcovina, PhD, ScD; Greg Strylewicz, MS

ECG Reading Center, EPICARE, Wake Forest University School of Medicine Ronald J. Prineas, MD, PhD; Zhu-Ming Zhang, MD; Charles Campbell, AAS, BS; Sharon Hall

Diet Assessment Center, University of South Carolina, Arnold School of Public Health, Center for Research in Nutrition and Health Disparities Elizabeth J Mayer-Davis, PhD; Cecilia Farach, DrPHFederal Sponsors National Institute of Diabetes and Digestive and Kidney Diseases: Barbara

Harrison, MS; Susan Z. Yanovski, MD; Van S. Hubbard, MD PhD

National Heart, Lung, and Blood Institute: Lawton S. Cooper, MD, MPH; Eva

Obarzanek, PhD, MPH, RD; Denise Simons-Morton, MD, PhD

Centers for Disease Control and Prevention: David F. Williamson, PhD; Edward W. Gregg, PhDFunding and Support

This study is supported by the Department of Health and Human Services through the following cooperative agreements from the National Institutes of Health: DK57136, DK57149, DK56990, DK57177, DK57171, DK57151, DK57182, DK57131, DK57002, DK57078, DK57154, DK57178, DK57219, DK57008, DK57135, and DK56992. The following federal agencies have contributed support: National Institute of Diabetes and Digestive and Kidney Diseases; National Heart, Lung, and Blood Institute; National Institute of Nursing Research; National Center on Minority Health and Health Disparities; Office of Research on Women's Health; and the Centers for Disease Control and Prevention. This research was supported in part by the Intramural Research Program of the National Institute of Diabetes and Digestive and Kidney Diseases. The Indian Health Service (I.H.S.) provided personnel, medical oversight, and use of facilities. The opinions expressed in this paper are those of the authors and do not necessarily reflect the views of the I.H.S. or other funding sources.

Additional support was received from The Johns Hopkins Medical Institutions Bayview General Clinical Research Center (M01-RR-02719); the Massachusetts General Hospital Mallinckrodt General Clinical Research Center (M01-RR01066); the University of Colorado Health Sciences Center General Clinical Research Center (M01 RR00051) and Clinical Nutrition Research Unit (P30 DK48520); the University of Tennessee at Memphis General Clinical Research Center (M01RR00211-40); the University of Pittsburgh General Clinical Research Center (M01 RR000056 44) and NIH grant (DK 046204); and the University of Washington/VA Puget Sound Health Care System Medical Research Service, Department of Veterans Affairs.

The following organizations have committed to make major contributions to Look AHEAD: Federal Express; Health Management Resources; Johnson \& Johnson, LifeScan Inc;; Optifast-Novartis Nutrition; Roche Pharmaceuticals; Ross Product Division of Abbott Laboratories; Slim-Fast Foods Company; and Unilever.

\section{Author details}

'Department of Epidemiology, Columbia Mailman School of Public Health, New York, NY, USA. ${ }^{2}$ Department of Epidemiology, Johns Hopkins Bloomberg School of Public Health, Baltimore, MD, USA. ${ }^{3}$ Division of General Internal Medicine, Johns Hopkins School of Medicine, Baltimore, MD, USA. ${ }^{4}$ Department of Biostatistics, Johns Hopkins Bloomberg School of Public Health, Baltimore, MD, USA. ${ }^{5}$ Division of Internal Medicine, University of Pittsburgh, Pittsburgh, PA, USA. 'Department of Medicine, St. Luke'sRoosevelt Hospital Center, New York, NY, USA. 'Division of General Internal Medicine and Health Services Research, Department of Medicine, David Geffen School of Medicine at UCLA, Los Angeles, CA, USA. ${ }^{8}$ Department of Psychiatry, University of Pennsylvania, Philadelphia, PA, USA.

\section{Authors' contributions}

TLG-W and FLB, were responsible for the conception and design of the study. KB-R was responsible for the data management and data analysis. LP advised on the statistical analysis. TLG-W drafted the manuscript. KB-R, JW-T, $J P, F P-S, A F B, L, F L B$ were responsible for critical review of the manuscript and interpretation of findings. All authors are responsible for the final version of the manuscript.

\section{Competing interests}

The authors declare that they have no competing interests.

Received: 5 May 2010 Accepted: 19 May 2011 Published: 19 May 2011

\section{References}

1. O'Campo P, Salmon C, Burke J: Neighbourhoods and mental well-being: What are the pathways? Health Place 2008.

2. Galea S, Ahern J, Rudenstine S, Wallace Z, Vlahov D: Urban built environment and depression: a multilevel analysis. J Epidemiol Community Health 2005, 59:822-827.

3. Kubzansky LD, Subramanian SV, Kawachi I, Fay ME, Soobader MJ, Berkman LF: Neighborhood contextual influences on depressive symptoms in the elderly. Am J Epidemiol 2005, 162:253-260.

4. Gary TL, Stark SA, LaVeist TA: Neighborhood characteristics and mental health among African Americans and whites living in a racially integrated urban community. Health Place 2007, 13:569-575.

5. Echeverria S, ez-Roux AV, Shea S, Borrell LN, Jackson S: Associations of neighborhood problems and neighborhood social cohesion with mental health and health behaviors: The Multi-Ethnic Study of Atherosclerosis. Health Place 2008.

6. Browning CR, Cagney KA: Neighborhood structural disadvantage, collective efficacy, and self-rated physical health in an urban setting. J Health Soc Behav 2002, 43:383-399.

7. Balfour JL, Kaplan GA: Neighborhood environment and loss of physical function in older adults: evidence from the Alameda County Study. Am J Epidemiol 2002, 155:507-515.

8. Diez Roux AV, Mair C: Neighborhoods and health. Ann N Y Acad Sci 2010, 1186:125-145.

9. Lustman PJ, Griffith LS, Gavard JA, Clouse RE: Depression in Adults with Diabetes. Diabetes Care 1992, 15:1631-1639.

10. Hill-Briggs F, Gary TL, Hill MN, Bone LR, Brancati FL: Health-related quality of life in urban African Americans with type 2 diabetes. $J$ Gen Intern Med 2002, 17:412-419.

11. Gary-Webb TL, Baptiste-Roberts K, Pham L, Wesche-Thobaben J, Patricio J, Pi-Sunyer FX, et al: Neighborhood and weight-related health behaviors in the Look AHEAD (Action for Health in Diabetes) study. BMC Public Health 2010, 10:312.

12. Ryan DH, Espeland MA, Foster GD, Haffner SM, Hubbard VS, Johnson KC, et al: Look AHEAD (Action for Health in Diabetes): design and methods for a clinical trial of weight loss for the prevention of cardiovascular disease in type 2 diabetes. Control Clin Trials 2003, 24:610-628.

13. Bray $G$, Gregg E, Haffner S, Pi-Sunyer XF, Wagenknecht LE, Walkup M, et al: Baseline characteristics of the randomised cohort from the Look AHEAD (Action for Health in Diabetes) study. Diab Vasc Dis Res 2006, 3:202-215.

14. Diez Roux AV, Jacobs DR, Kiefe Cl: Neighborhood characteristics and components of the insulin resistance syndrome in young adults: the coronary artery risk development in young adults (CARDIA) study. Diabetes Care 2002, 25:1976-1982.

15. Winkleby MA, Cubbin C: Influence of individual and neighbourhood socioeconomic status on mortality among black, Mexican-American, and white women and men in the United States. J Epidemiol Community Health 2003, 57:444-452.

16. Krieger N, Chen JT, Waterman PD, Soobader MJ, Subramanian SV, Carson R: Geocoding and monitoring of US socioeconomic inequalities in mortality and cancer incidence: does the choice of area-based measure and geographic level matter?: the Public Health Disparities Geocoding Project. Am J Epidemiol 2002, 156:471-482.

17. Ware JE, Sherbourne CD: The MOS 36-Item Short-Form Health Survey (SF36): I. Conceptual Framework and Item Selection. Medical Care 1992, 30:473-484.

18. SF-36 Scoring Rules: (Version1.1). New England Medical Center Hospital, Inc. All Rights Reserved; 1991

19. Ware JE, Kosinski M: SF-36 Physical \& Mental Health Summary Scales: A Manual for Users of Version 1. Lincoln, Rl, QualityMetric Incorporated; Second 2001, 2-119. 
20. Beck AT, Ward CH, Mendelson M, Mock J, Erbaugh J: An Inventory For Measuring Depression. Arch Gen Psychiatry 1961, 4:53-63.

21. Diez-Roux AV: Multilevel analysis in public health research. Annu Rev Public Health 2000, 21:171-192.

22. Bingenheimer JB, Raudenbush SW: Statistical and substantive inferences in public health: issues in the application of multilevel models. Annu Rev Public Health 2004, 25:53-77.

23. Klassen AC, Curriero FC, Hong JH, Williams C, Kulldorff M, Meissner Hl, et al: The role of area-level influences on prostate cancer grade and stage at diagnosis. Prev Med 2004, 39:441-448.

24. Gary TL, Crum RM, Cooper-Patrick L, Ford D, Brancati FL: Depressive symptoms and metabolic control in African-Americans with type 2 diabetes. Diabetes Care 2000, 23:23-29.

25. Mair C, ez Roux AV, Galea S: Are neighbourhood characteristics associated with depressive symptoms? A review of evidence. J Epidemiol Community Health 2008, 62:940-6, 8.

26. Kim D: Blues from the neighborhood? Neighborhood characteristics and depression. Epidemiol Rev 2008, 30:101-117.

27. Mair C, ez Roux AV, Osypuk TL, Rapp SR, Seeman T, Watson KE: Is neighborhood racial/ethnic composition associated with depressive symptoms? The multi-ethnic study of atherosclerosis. Soc Sci Med 2010 71:541-550.

\section{Pre-publication history}

The pre-publication history for this paper can be accessed here: http://www.biomedcentral.com/1471-2458/11/349/prepub

doi:10.1186/1471-2458-11-349

Cite this article as: Gary-Webb et al:: Neighborhood Socioeconomic Status, Depression, and Health Status in the Look AHEAD (Action for Health in Diabetes) Study. BMC Public Health 2011 11:349.

\section{Submit your next manuscript to BioMed Central and take full advantage of:}

- Convenient online submission

- Thorough peer review

- No space constraints or color figure charges

- Immediate publication on acceptance

- Inclusion in PubMed, CAS, Scopus and Google Scholar

- Research which is freely available for redistribution

Submit your manuscript at www.biomedcentral.com/submit 